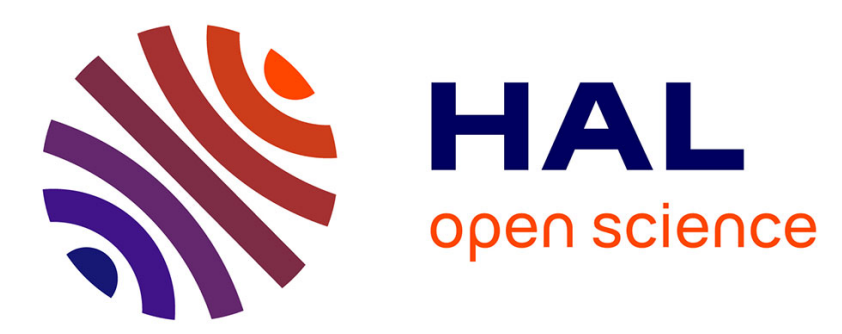

\title{
Archaeal flagellar ATPase motor shows ATP-dependent hexameric assembly and activity stimulation by specific lipid binding
}

\author{
Abhrajyoti Ghosh, Sophia Hartung, Chris van Der Does, John A Tainer, \\ Sonja-Verena Albers
}

\section{To cite this version:}

Abhrajyoti Ghosh, Sophia Hartung, Chris van Der Does, John A Tainer, Sonja-Verena Albers. Archaeal flagellar ATPase motor shows ATP-dependent hexameric assembly and activity stimulation by specific lipid binding. Biochemical Journal, 2011, 437 (1), pp.43-52. 10.1042/BJ20110410 . hal00600759

\section{HAL Id: hal-00600759 \\ https://hal.science/hal-00600759}

Submitted on 16 Jun 2011

HAL is a multi-disciplinary open access archive for the deposit and dissemination of scientific research documents, whether they are published or not. The documents may come from teaching and research institutions in France or abroad, or from public or private research centers.
L'archive ouverte pluridisciplinaire HAL, est destinée au dépôt et à la diffusion de documents scientifiques de niveau recherche, publiés ou non, émanant des établissements d'enseignement et de recherche français ou étrangers, des laboratoires publics ou privés. 
Ghosh et.al.

Archaeal flagellar ATPase motor shows ATP-dependent hexameric assembly and activity stimulation by specific lipid binding

Abhrajyoti Ghosh ${ }^{1}$, Sophia Hartung ${ }^{2}$, Chris van der Does ${ }^{3}$, John A. Tainer ${ }^{2}$, and Sonja-Verena Albers ${ }^{1 *}$

${ }^{1}$ Molecular Biology of Archaea, Max Planck Institute for terrestrial Microbiology, Karl-von-Frisch-Strasse 10, 35043 Marburg, Germany

${ }^{2}$ Department of Molecular Biology, The Scripps Research Institute, La Jolla, CA 92037, USA and Lawrence Berkeley National Laboratory, Berkeley, CA 94720, USA

${ }^{3}$ Department of Ecophysiology, Max Planck Institute for terrestrial Microbiology, Karl-von-Frisch-Strasse 10, 35043 Marburg, Germany

"Correspondence to S.V. Albers, e-mail: albers@mpi-marburg.mpg.de, telephone: +496421178426 , fax: +496421178429

Running Title (75 characters:)

Archaeal flagellar ATPase motor hexamer assembly and lipid stimulation

keywords:

secretion superfamily ATPase,

type II/IV secretion ATPase,

Sulfolobus acidocaldarius,

Type IV pili,

T2S/T4P ATPase superfamily,

Lipid activation 
Ghosh et.al.

\begin{abstract}
Microbial motility frequently depends on flagella or type IV pili. Using recently developed archaeal genetic tools, archaeal flagella and its assembly machinery have been identified. Archaeal flagella are functionally similar to bacterial flagella and their assembly systems are homologous to type IV pili assembly systems of Gram negative bacteria. Therefore, elucidating their biochemistry may result in insights in both archaea and bacteria. Flal, a critical cytoplasmic component of the archaeal flagella assembly system in Sulfolobus acidocaldarius, is a member of the type II/IV secretion system ATPase superfamily, and is proposed to be bi-functional in driving flagella assembly and movement. Here we show that purified Flal is a $\mathrm{Mn}^{2+}$ dependent ATPase that binds MANT-ATP with a high affinity and hydrolyses ATP in a cooperative manner. Flal has an optimum $\mathrm{pH}$ and temperature of 6.5 and $75^{\circ} \mathrm{C}$ for ATP hydrolysis. Remarkably, archaeal, but not bacterial lipids, stimulated the ATPase activity of Flal 3-4 fold. Analytical gel filtration indicated that Flal undergoes nucleotide-dependent oligomerization. Furthermore, small angle X-ray scattering (SAXS) analysis revealed an ATP-dependent hexamerization of Flal in solution. These results report the first detailed biochemical analyses of the motor protein of an archaeal flagellum.
\end{abstract}


Ghosh et.al.

\section{INTRODUCTION}

Motility is vitally important for most prokaryotes, and various mechanisms utilized by bacteria and archaea for motility have been described in recent years [1]. In bacteria, the two most commonly used mechanisms, movement via flagellar rotation as well as twitching using the extension and retraction of type IV pili (T4P) have been studied extensively [2-3]. This has led to the identification and characterization of many components required for the assembly and function of these systems. Very little however is known about the assembly of archaeal surface appendages like flagella and pili, although a diverse variety has been identified [4-5]. In Halobacterium salinarum flagella have been reported to be involved in swimming motility [6-8] and shown to be important for swarming on solid surfaces in methanogens and Sulfolobus solfataricus [7-8]. Recent evidence further revealed that flagella in $S$. solfataricus are involved not only in surface attachment, but also in late phases of bio-film maturation [9-11].

Remarkably, available structural and genetic information indicated that the archaeal flagella are more similar to bacterial T4P than to the bacterial flagella [4, 12-14]. Genetic analysis in different flageliated archaea recently has been used to identify a genetic locus that encodes an archaeal flagella assembly system (AFAS) [15]. Within different archaea, this genetic locus contains seven to thirteen genes. Usually it contains several flagellin genes (flaA and/or flaB genes) followed by a conserved set of flagella-related protein genes (flaC-flaJ) [16]. The genetic locus in Sulfolobales, however, contains apart from the conserved set of flagella-related protein genes only one gene encoding a flagellin. Several components of the archaeal flagella assembly machinery show homology to proteins involved in type IV pilus (T4P) assembly, type II secretion (T2S), and type IV secretion (T4S) systems of Gram negative bacteria [4, 7, 17-21]. T2S systems in bacteria play a role in the secretion of toxins and enzymes, e.g, the cholera toxin of Vibrio cholerae [22], whereas T4S systems are used for the transport of DNA to either bacterial or eukaryal host cells as exemplified by Agrobacterium tumefaciens [23]. T4P are involved in a variety of functions such as twitching motility and cell adhesion which are essential for the pathogenicity of several harmful bacteria [14]. All three systems have significant structural and functional similarities pointing to a common origin [18]. Interestingly, the subunits that are found to be similar in those systems are also present in the AFAS [24]. These components include pre-flagellin peptidases (e.g. PibD of $S$. solfataricus) [4], FlaJ, that has homology to the polytopic membrane protein found in T4P systems (e.g. PilG of Neisseria) [17-18, 25] and Flal, that has homology to type II secretion ATPases and T4P assembly ATPases (e.g. PilB, GspE, EpsE, HP0525) [18-19, 26-28]. Recently, three-dimensional reconstructions of electron microscopic images of archaeal flagella and of T4P revealed a considerable structural homology with type IV pili [13, 20-21, 29-30]. These collective results showed that the archaeal flagella and T4P systems show strong similarities and might be evolutionary related.

A central component found in both systems is the cytoplasmic ATPase that provides the energy. These ATPases belong to the "secretion superfamily ATPase" or "type II/IV secretion ATPase" family [18]. Proteins of this superfamily function in multiple macromolecular transport systems in bacteria and archaea, like T2S, T4S, T4P assembly, and in archaeal flagella assembly 
Ghosh et.al.

systems $[14,18,26-27,31]$. Members of this superfamily contain characteristic conserved motifs such as Walker A, Walker B and P-loop motifs (GX4GK(S/T)), which are involved in nucleotide binding. They also contain the Asp box motif involved in divalent cation binding and the His box motif possibly is involved in stabilization of the nucleotide binding [32].

Based on their sequence similarities, secretion ATPases were grouped into different clusters, including clusters for ATPases from T2S systems, T4P systems, and a cluster for archaeal ATPases [18]. Although both T2S and T4S are powered by secretion ATPases, the basic mechanism is different for these secretion systems. In T2S system, the ATPase, GspE is involved in assembly of the 'pseudopilin' filament called pseudopilus. In comparison, T4S system ATPases may function as protein translocators by interacting with the secreted protein already folded in the cytoplasm. In T4P assembly systems, two ATPases, PilB and PilT are present and function in assembly and disassembly of the pilus, respectively [33-35]. Interestingly, the amino acid sequence of Flal resembles bacterial T2S and T4P type ATPases, suggesting a common evolutionary root for all these secretion ATPases.

The archaeal flagellum is able to move clockwise and counterclockwise, which results in a switch in swimming direction [36]. The question arises how a type IV pilus would be able to move in this fashion, as normally twitching motility is conferred by filament assembly and disassembly and not by any rotational movement. Because Flal is the only ATPase identified in archaeal flagella operons, it is most likely involved in two functions: first in the assembly process and secondly in the movement leading to motility. Therefore, it is important to understand how this protein can perform both functions.

The specific role of the secretion ATPase in archaeal flagella assembly systems has not been addressed before. It has been shown for Methanococcus maripaludis and Halobacterium salinarum that Flal deletion mutants are impaired in assembly of their flagella [16, 19, 37], but neither have been biochemically characterized. The relation between ATP binding and hydrolysis and flagellum assembly and rotation remains unknown. In the present work, the secretion ATPase Flal from Sulfolobus acidocaldarius, a thermoacidophilic crenarchaeon that grows optimally at $70-80^{\circ} \mathrm{C}$ and $\mathrm{pH} 2-3$, is biochemically and structurally characterized. 
Ghosh et.al.

\section{MATERIALS AND METHODS}

Construction of a Flal overexpression vector. To enable expression of non tagged Flal or Flal with an N-terminal His-tag, the flal gene (saci_1173) was amplified by PCR from genomic DNA of Sulfolobus acidocaldarius DSM639 using primer-pairs Flal 713 /Flal 714 or Flal $728 /$ Flal729 and cloned as $\mathrm{Ndel} / \mathrm{BamHI}$ or EcoRI/Hindll fragment into plasmid pETDuet-1(Novagen), yielding plasmids pSVA251 and pSVA263 respectively. For expression analysis, the respective vectors were transformed to Escherichia coli C43 cells containing the RIL Chlplasmid (Strategene) [38].

Site-directed mutagenesis of flal. Mutagenesis of flal was performed by overlap PCR on vector pSVA263. Mutants were created by changing $\mathrm{K}^{268}$ within the predicted Walker $A$ motif, $D^{290}$ within the Asp-box and $E^{336}$ within the Walker $B$ motif to alanines. The resultant plasmids were named pSVA265 $\left(\mathrm{K}^{268 \mathrm{~A}}\right)$, pSVA307 $\left(\mathrm{D}^{290 \mathrm{~A}}\right)$, pSVA308 $\left(\mathrm{E}^{336 \mathrm{~A}}\right)$ and pSVA314 $\left(\mathrm{K}^{268 \mathrm{~A}}, \mathrm{E}^{336 \mathrm{~A}}\right)$. Sequences of the oligonucleotides used for mutagenesis are listed Table 1.

Expression of recombinant proteins in Escherichia coli. Ten milliliters of an overnight culture of E. coli C43 cells containing the RIL plasmid [38] and one of the respective over-expression plasmids was used to inoculate 1 liter of Luria-Bertani medium containing ampicillin $(100 \mu \mathrm{g} / \mathrm{ml})$ and chloramphanicol $(34 \mu \mathrm{g} / \mathrm{ml})$. Cells were grown at $37^{\circ} \mathrm{C}$ to an optical density at $600 \mathrm{~nm}$ of 0.6 was reached, at which moment $1 \mathrm{mM}$ isopropyl- $\beta$-D-thiogalactopyranoside (IPTG) was added. The temperature was reduced to $16^{\circ} \mathrm{C}$, and growth was continued over-night to reduce inclusion body formation. The cells were collected by centrifugation, resuspended in lysis buffer $(50 \mathrm{mM}$ HEPES$\mathrm{NaOH}, \mathrm{pH} 7.5,150 \mathrm{mM} \mathrm{NaCl}, 10 \%$ glycerol) containing the complete EDTAfree protease inhibitor cocktail (1 tablet/ $50 \mathrm{ml}$ of lysate; Roche, Manheim, Germany), frozen in liquid nitrogen and stored at $-80^{\circ} \mathrm{C}$.

Purification of recombinant proteins. Before purification, frozen resuspended cell pellets were thawed on ice. Cells were lysed by sonication with a Sonoplus HD3100 sonicator (Bandelin Sonorex Biotechnique, Germany) using probe HD3100. Cell debris was removed by centrifugation at $6000 \times \mathrm{g}$ for 15 min followed by centrifugation at $150,000 \times \mathrm{g}$ for $30 \mathrm{~min}$ at $4^{\circ} \mathrm{C}$ in a Optima ${ }^{\mathrm{TM}}$ MAX-XP ultracentrifuge (rotor MLA 55) (Beckman Coulter, USA) to remove the membranes. The supernatant was incubated at $70^{\circ} \mathrm{C}$ for $20 \mathrm{~min}$ in a water bath. The sample was cooled down on ice and precipitated proteins were removed by centrifugation at $150,000 \times \mathrm{g}$ for $30 \mathrm{~min}$ at $4^{\circ} \mathrm{C}$ in a Optima ${ }^{\mathrm{TM}}$ MAX-XP ultracentrifuge (rotor MLA 55) (Beckman Coulter, USA). For purification of His-tagged proteins, the supernatant was applied to a $\mathrm{Ni}^{2+}$ affinity column (Native IMAC) on the Profinia ${ }^{T M}$ protein purification system (BioRad Laboratories, Inc, USA). Bound protein was eluted in lysis buffer containing $500 \mathrm{mM}$ imidazole. The eluted fraction was dialyzed overnight at $4^{\circ} \mathrm{C}$ against $50 \mathrm{mM}$ HEPES-NaOH, $\mathrm{pH} 7.5,150 \mathrm{mM} \mathrm{NaCl}, 10 \%$ glycerol. The dialyzed fraction was loaded on a Superdex 200 10/300 gel filtration column on an AKTA-Purifier system (GE Health Care, Germany), equilibrated with 50 $\mathrm{mM}$ HEPES-NaOH, pH 7.5, $150 \mathrm{mM} \mathrm{NaCl}, 10 \%$ glycerol (flow rate 0.5 $\mathrm{ml} / \mathrm{min}$ ). The untagged Flal was expressed, sonicated and heat treated, as described above. The protein was then precipitated at room temperature with 
Ghosh et.al.

$20 \%$ ammonium sulfate (w/v) for $30 \mathrm{~min}$. The precipitated protein was resuspended in buffer Blue A (50mM Tris- $\mathrm{HCl}, \mathrm{pH} 8.0,200 \mathrm{mM} \mathrm{NaCl}, 2 \mathrm{mM}$ EDTA) and loaded on a $5 \mathrm{ml}$ HiTrap BLUE column in the AKTA-Purifier system (GE Health Care, Germany). The column was washed with buffer Blue $A$ and the bound protein was eluted with buffer Blue $B(50 \mathrm{mM}$ Tris- $\mathrm{HCl}, \mathrm{pH}$ 8.0, $1 \mathrm{M} \mathrm{NaCl}, 2 \mathrm{mM}$ EDTA). The eluted protein was further purified on a $5 \mathrm{ml}$ HiTrap PHENYL column. The protein was eluted using a gradient from buffer Blue $\mathrm{B}$ to buffer PHENYL (50 mM Tris- $\mathrm{HCl}, \mathrm{pH} 8.0,2 \mathrm{mM}$ EDTA). The eluted protein was then concentrated $(<2 \mathrm{ml})$ using an amicon concentrator system (Milipore, USA), and loaded on to a Superose 6 10/300 size-exclusion column pre-equilibrated with PHENYL buffer and eluted with $50 \mathrm{mM}$ HEPES-NaOH buffer, pH 7.5 containing $150 \mathrm{mM} \mathrm{NaCl}$.

Protein purity was monitored by reducing sodium dodecyl sulphatepolyacrylamide gel electrophoresis (SDS-PAGE). Gels were stained with Biosafe (BioRad) protein stain. Protein concentration was determined with the Bio Rad protein assay dye-dependent reagent (Bio Rad).

ATPase assay. ATPase activities were measured using the malachite green assay, as described previously [39]. Briefly, purified protein $(2 \mu \mathrm{g})$ was preheated for 2 min in $100 \mu$ lassay buffer (50 mM HEPES, pH 7.5, $150 \mathrm{mM} \mathrm{NaCl}$ and $5 \mathrm{mM} \mathrm{MgCl}_{2}$ ). Reactions were initiated by addition of $1 \mathrm{mM} \mathrm{ATP}$, and incubated for $5 \mathrm{~min}$ at $70^{\circ} \mathrm{C}$. The reaction was stopped by freezing in liquid nitrogen. The amount of released inorganic phosphate was determined using the malachite green assay. The data were corrected for non-enzymatic ATP hydrolysis. To determine the activity of Flal as a function of temperature, $\mathrm{pH}$, nucleotides and divalent cations, the assay was performed at different temperatures, in different buffers $(50 \mathrm{mM}$ Citrate, $\mathrm{pH}$ 3.0-5.5; MES, $\mathrm{pH}$ 6.06.5; HEPES, $\mathrm{pH}$ 7.0-7.5; Tris- $\mathrm{Cl}$, $\mathrm{pH}$ 8.0-9.5), with different NTPs (5 mM of ATP, GTP, CTP, and UTP), and in the absence of, or with different divalent cations ( $5 \mathrm{mM} \mathrm{Na}$-EDTA or $5 \mathrm{mM} \mathrm{MnCl}_{2}$ or $5 \mathrm{mM} \mathrm{CaCl}_{2}$ ) respectively. The ATPase activity was determined as a function of the ATP concentration, and the resulting data were fitted to the Hill equation $y=\left(a x^{n} /\left(b^{n}+x^{n}\right)\right)$, to obtain the $\mathrm{V}_{\max }(\mathrm{a})$, the dissociation constant, $\mathrm{K}_{0.5}(\mathrm{~b})$ and the hill coefficient $(\mathrm{n})$. To analyze the effect of tetraether lipids on ATP-hydrolysis by Flal, total lipids of $S$. acidocaldarius were extracted, as described previously [40] . The ATPase activity of Flal (1 $\mathrm{\mu M}$ purified protein) was measured as described above in the presence of different concentrations of isolated lipids $(40,80,100,200$, 400 , and $800 \mu \mathrm{g}$ ).

MANT-ATP binding assay. Binding of MANT-ATP (2'-/3'-O-(N'Methylanthraniloyl)adenosine-5'-O-triphosphate) was followed by FRET measurements using a temperature-controlled ISS PC1 spectrofluorometer (ISS Inc., USA). The excitation wavelength was set to 285 and the emission spectrum was recorded from 400 to $500 \mathrm{~nm}$. The slit widths for the excitation and the emission beam were set to $1 \mathrm{~nm}$. MANT-ATP binding affinities were determined by titrating $0.1 \mu \mathrm{M}$ of protein with increasing concentration of MANT-ATP $(0.125 \mu \mathrm{M}-25 \mu \mathrm{M})$ at $25^{\circ} \mathrm{C}$ in binding buffer (50 mM HEPES, pH $7.5,150 \mathrm{mM} \mathrm{NaCl}, 5 \mathrm{mM} \mathrm{MnCl}_{2}$ ). Fluorescence spectra were corrected for the fluorescence of unbound MANT-ATP, and the resulting fluorescence at 450 
Ghosh et.al.

$n m$ was fitted to the Hill equation $y=\left(a x^{n} /\left(b^{n}+x^{n}\right)\right)$, to obtain the $\Delta F_{\max }(a)$, the dissociation constant, $\mathrm{K}_{0.5}(\mathrm{~b})$ and the hill coefficient $(\mathrm{n})$.

Liposome pull-down assay. The liposome pull-down assay was performed as described previously [41]. Briefly, isolated and dried tetraether lipids from $S$. acidocaldarius were hydrated with liposome-binding buffer (50 mM HEPES, $\mathrm{pH} 7.5,150 \mathrm{mM} \mathrm{NaCl}$ and $5 \mathrm{mM} \mathrm{MgCl}_{2}$ ) and vigorously vortexed to ensure dispersion of the various lipids in a Sonoplus HD3100 sonicator (Bandelin Sonorex Biotechnique, Germany) using probe HD3100. Liposomes were collected from the supernatant after centrifugation $(2,500 \mathrm{xg}$ for $5 \mathrm{~min})$ and used in subsequent assays. To perform experiments with $E$. coli polar lipids, a liquid form of polar lipid mixture was purchased from Avanti Polar Lipids, Inc. (Alabama, USA). The polar lipids were dried in a vacuum desiccator for approximately $5 \mathrm{~h}$. Dried lipids were hydrated with liposome-binding buffer (50 $\mathrm{mM}$ HEPES, $\mathrm{pH} 7.5,150 \mathrm{mM} \mathrm{NaCl}$ and $5 \mathrm{mM} \mathrm{MgCl}_{2}$ ) and treated in a similar manner as tetraether lipids to generate differentially sized liposomes for pulldown assay.

The pull-down assay was performed separately with $1 \mu \mathrm{M}$ of $6 x$ Histagged Flal, $\mathrm{Flal}^{\mathrm{K} 268 \mathrm{~A}}$ or $\mathrm{Flal}^{\mathrm{E} 336 \mathrm{~A}}$ purified protein. The proteins were preincubated with $1 \mathrm{mM}$ ATP at $25^{\circ} \mathrm{C}$ for $30 \mathrm{~min}$ in the nucleotide binding buffer (50 mM HEPES, $\mathrm{pH} 7.5,150 \mathrm{mM} \mathrm{NaCl}$ and $5 \mathrm{mM} \mathrm{MgCl}_{2}$ ) in a total volume of $100 \mu \mathrm{L}$. Liposomes were added to a final lipid concentration of $80 \mu \mathrm{g} / \mathrm{ml}$ and reactions were incubated at room temperature for $1 \mathrm{~h}$. By centrifugation at $100,000 \times \mathrm{g}$ in a Beckman TLA100.3 rotor in a Optima $^{\text {TM }}$ MAX-XP ultracentrifuge (Beckman Coulter, USA) at $4^{\circ} \mathrm{C}$ for $30 \mathrm{~min}$, the lipid vesicles were separated from the soluble fraction. The supernatant and pellet were analyzed on a $11 \%$ polyacrylamide gel and visualized with Coommassie blue.

Analytical gel-filtration. Purified Flal was concentrated to $1.0 \mathrm{mg} / \mathrm{ml}$ in $50 \mathrm{mM}$ HEPES-NaOH buffer, $\mathrm{pH} 7.5,150 \mathrm{mM} \mathrm{NaCl}$ by centrifugation in an amicon filter (10 kDa cutoff; Millipore). The sample was then pre-incubated at $50^{\circ} \mathrm{C}$ for $10 \mathrm{~min}$ followed by incubation at $4^{\circ} \mathrm{C}$ for $6 \mathrm{~h}$ with either $1 \mathrm{mM}$ AMP-PNP (Adenylyl-imidodiphosphate) or ADP in the presence of $10 \mathrm{mM} \mathrm{MgCl}$. The sample was loaded on a Superdex $20010 / 300$ column on the AKTA purifier system as described above. All the fractions were analyzed on SDS-PAGE and immunoblotted using anti-His antibodies (Abcam).

Small angle $X$-ray scattering (SAXS) analyses. SAXS data were collected at the ALS beamline 12.3.1 (SIBYLS, Lawrence Berkeley National Laboratory, Berkeley, CA) [42]. The scattering vector is defined as $q=4 \pi \sin \theta / \lambda$, where $2 \theta$ is the scattering angle. Prior to SAXS data collection Flal wild-type and Flal $^{\mathrm{E} 336 \mathrm{~A}}$ were applied to a superose 6 size exclusion column in $20 \mathrm{mM}$ Tris, pH 7.0, $200 \mathrm{mM} \mathrm{NaCl}$ and $20 \mathrm{mM}$ Tris pH 7.0, $200 \mathrm{mM} \mathrm{NaCl}, 1 \mathrm{mM} \mathrm{ATP}, 2.5$ $\mathrm{mM} \mathrm{MgCl}$, respectively. Fractions from the column were analyzed directly and after 2-fold and 4-fold concentration of the sample using Corning Spin- $X$ concentrators. All experiments were performed at $20^{\circ} \mathrm{C}$, and data were processed as described [43]. The data acquired at short and long time exposure (1 and $10 \mathrm{~s}$ ) were merged for calculations using the entire scattering spectrum. The experimental SAXS data for different protein concentrations were investigated for aggregation using Guinier plots [44]. The program 
Ghosh et.al.

GNOM [45] was used to compute the pair distance distribution functions, $P(r)$. This approach also provided the maximum dimension of the macromolecule, $D_{\max }$. The overall shapes were restored from the experimental data using the program GASBOR and averaging of 15 independent structures using the program DAMAVER [46]. Molecular graphics images were produced using the UCSF Chimera package from the Resource for Biocomputing, Visualization, and Informatics at the University of California, San Francisco (supported by NIH P41 RR-01081, Pettersen et al, 2004). Theoretical scattering curves from crystal structures were calculated using FoXS [47]. 
Ghosh et.al.

\section{RESULTS}

\section{Expression, purification and biochemical characterization of Flal}

Both His-tagged and wt Flal were expressed in $E$. coli and purified to homogeneity. Purified Flal was analyzed by SDS-PAGE, and found to be over $99 \%$ pure. Flal was tested for the ability to hydrolyze ATP under different conditions. The optimal conditions for ATP hydrolysis by Flal were determined to be $\mathrm{pH} 6.5$ and $75^{\circ} \mathrm{C}$ (Figure 1A and 1B), which are close to the cytoplasmic $\mathrm{pH}$ and the optimal growth temperature of Sulfolobus acidocaldarius. $\mathrm{Mn}^{2+}$ was the preferred divalent cation for ATP hydrolysis (Figure $1 \mathrm{C}$ ), as was observed for other secretion ATPases [26]. Considerable activity was however also detected in the presence of $\mathrm{Ca}^{2+}$ and $\mathrm{Mg}^{2+}$, respectively (Figure 1C). Flal hydrolyzed ATP with the highest rate, but it was also able to hydrolyze GTP, CTP and UTP (Figure 1D), as seen for other ATPases. No conversion of ADP to AMP was detected (Figure 1D).

To determine the concentration dependency of ATP hydrolysis, the ATP hydrolysis rate was determined as a function of the ATP concentration ( Figure $1 \mathrm{E}$ and $1 \mathrm{~F}$ ). The fit of the data with the Hill equation resulted in a $\mathrm{V}_{\max }$ of $32 \mathrm{nmol} \mathrm{Pi} / \mathrm{mg}$ protein/min, a $\mathrm{K}_{0.5}$ of $10 \mathrm{mM}$ and a Hill coefficient of 2.0 . The Hill coefficient demonstrates that ATP hydrolysis is cooperative, suggesting that Flal oligomerizes during ATP hydrolysis. Flal had a very low turn-over rate $(1 \mathrm{ATP} / \mathrm{min})$, consistent with observations on other secretion ATPases [26]. Most of these ATPases are part of large macromolecular assemblies and other protein components of these complexes, for example, the membrane protein EpsL in type II secretion system, stimulate the nucleotide hydrolyzing activity of the ATPases [48-49]. Furthermore, lipids can enhance the ATPase activity of these proteins [48].

To assess the influence of archaeal tetraether lipids on the Flal ATPase activity, the specific activity of the enzyme was measured in the presence of increasing concentrations of $S$. acidocaldarius tetraether lipids (Figure 2). Remarkably, the tetraether lipids increased the ATPase activity 3-4 fold, whereas the addition of an E. coli total lipid extract only led to a 1.5 fold stimulation of the ATPase activity. This is in contrast to EpsE, which activity was only activated in the presence of both lipids and the cytoplasmic loops of the corresponding inner membrane protein and not by lipids alone [48].

\section{Active site mutants of Flal}

Secretion ATPases contain key conserved motifs for the Walker A and B motifs and the Asp-box. Alignment of S. acidocaldarius Flal with GspE, i.e. a secretion ATPase of Archaeoglobus fulgidus [27], led to the identification of these motifs in Flal (Figure S1). To determine the effects of mutations in these motifs, the lysine of the Walker $A\left(K^{268 A}\right)$, the glutamate of the Walker $B$ $\left(E^{336 A}\right)$, and the aspartate of the Asp-box $\left(D^{290 A}\right)$ were mutated. A double mutant of the Walker A and B mutations Flal ${ }^{\mathrm{K} 268 \mathrm{~A} / \mathrm{E} 336 \mathrm{~A}}$ was also constructed. These mutants were expressed and purified, and the expression levels and final purity of these proteins were equal to wt Flal (data not shown). The different mutants were tested for their ability to hydrolyze ATP (Figure 3A), and for their ability to bind the fluorescent ATP analog MANT-ATP ( Figure 3B). Remarkably, mutation of the lysine of the Walker A motif to an alanine only resulted in a reduction of approximately $50 \%$ of ATP-hydrolysis 
Ghosh et.al.

compared to wild type Flal, while mutagenesis of the aspartate of the Asp-box had no effect on ATP hydrolysis. By substituting $E^{336}$ of the Walker $B$ with an alanine, ATPase activity was reduced upto $90 \%$. Analysis of the crystal structure of GspE from $A$. fulgidus ( $\mathrm{gdb}$ : 2OAP) revealed that the glutamate residue $\left(E^{336}\right.$ in $\left.\mathrm{Flal}\right)$ in the Walker $B$ motif is involved in the interaction with Mg-ATP and also is highly conserved among secretion ATPases superfamily members from various archaeal species (Figure S1) [27]. Also for the Myxococcus xanthus PilT, which is the disassembly ATPase of the T4P assembly system, mutagenesis of the conserved glutamate residue in the Walker B box to alanine resulted in loss of ATPase activity [34]. Almost no ATP hydrolysis (2-3\%) was detected for the Flal ${ }^{\mathrm{K} 268 \mathrm{~A} / \mathrm{E} 336 \mathrm{~A}}$ double mutant.

The MANT-ATP binding assay demonstrated that wt Flal bound MANTATP with a $K_{d}$ of $0.46 \mu \mathrm{M}$, a fit of the data with the Hill equation resulted in a Hill coefficient of 0.9 , demonstrating that ATP binding, contrary to ATP hydrolysis was not co-operative. Remarkably, MANT-ATP binding to both the Walker B motif $\left(K_{d}=0.58 \mu \mathrm{M}\right)$ and Asp-box mutant $\left(K_{d}=0.43 \mu \mathrm{M}\right)$ was comparable to wt Flal, whereas binding to the Walker A mutant was strongly reduced $\left(K_{d}=9.6 \mu M\right)$. Thus our data showed that mutagenesis of the Asp-box residue of Flal does not have any effect on ATP binding and hydrolysis, while mutation of the Walker B motif does not affect ATP binding, but heavily abolishes ATP hydrolysis. Notably, mutagenesis of the Walker A motif results in a 20-fold lower binding affinity but an only 2-fold reduction of ATPase hydrolysis activity. Presumably, the Walker A box substitution, i.e. $\mathrm{K}^{268 \mathrm{~A}}$ in Flal, indirectly reduces ATPase activity by interfering with ATP binding. The Walker B box substitution on the other hand, i.e. $E^{336 A}$ in Flal, abolishes ATPase activity by directly interfering with the ATP hydrolysis, although ATP binding seems normal in this mutant $\left(E^{336 A}\right)$. Furthermore, the data suggest no role of the conserved $D^{290}$ in the Asp-box motif in ATP binding and hydrolysis.

\section{Oligomerization of Flal}

Members of the secretion ATPases superfamily can oligomerize into higher oligomeric structures [27,50-51]. To assess the oligomeric state of purified Flal (monomer molecular weight $55 \mathrm{kDa}$ ), his-tagged Flal was analyzed by size exclusion chromatography. Due to the presence of a small shoulder in the chromatogram, small amounts of a dimeric Flal seem to be present (Figure 4, fraction 13). To determine whether Flal could form higher oligomeric structures, the effect of nucleotide binding on Flal oligomerization was studied using the non-hydrolyzable ATP analog AMP-PNP. After preincubation with or without AMP-PNP and $\mathrm{Mg}^{2+}$, purified Flal was analyzed by size exclusion chromatography. Remarkably, after incubation with AMPPNP, Flal was eluted at estimated molecular weights of $330 \mathrm{kDa}$ and $55 \mathrm{kDa}$, respectively. This shows that Flal assembles in an oligomeric structurein a nucleotide-dependent manner in the presence of non-hydrolyzable ATP analogs. To ascertain that the same phenomenon occurs in Flal mutants, Flal with a mutation in either the Walker A motif (Flal $\left.{ }^{\mathrm{K} 268 \mathrm{~A}}\right)$ or the Walker B motif $\left(\right.$ Flal $\left.^{\mathrm{E} 336 \mathrm{~A}}\right)$, which showed a reduced $(\sim 50 \%)$ and very low $(\sim 10 \%)$ ATPase activity, respectively, were also analyzed. After incubation with ATP, a higher oligomeric form was observed only for the Flal protein containing a mutation in the Walker $\mathrm{B}\left(\mathrm{Flal}^{\mathrm{E} 336 \mathrm{~A}}\right)$, but not for the Flal with a mutation in the Walker $\mathrm{A}$ motif (Flal ${ }^{\mathrm{K} 268 \mathrm{~A}}$ ) (Figure S2). This demonstrated that Flal with a mutation in the 
Ghosh et.al.

Walker B motif (Flal ${ }^{\mathrm{E} 336 \mathrm{~A}}$ ) forms a stable oligomer after ATP binding. Therefore, wt Flal and Flal with a mutation in the Walker B motif (Flal ${ }^{\mathrm{E} 36 \mathrm{~A}}$ ) oligomerize upon ATP binding. However, the oligomerization potential of Walker B motif mutant (Flal ${ }^{-336 \mathrm{~A}}$ ) seems higher compared to wt Flal, suggesting a more stable complex formation with ATP by the Walker B mutant (Flal $^{\mathrm{E} 336 \mathrm{~A}}$ ) (Figure S2). As expected, incubation of either the wt Flal, or Flal with a mutation in either the Walker A motif (Flal ${ }^{\mathrm{K} 268 \mathrm{~A}}$ ) or the Walker B motif (Flal ${ }^{\mathrm{E} 36 \mathrm{~A}}$ ) with ADP did not result in oligomerization of Flal (data not shown).

\section{SAXS analysis of oligomerization states of Flal}

To further analyze the oligomeric structure of Flal, Small Angle X-ray Scattering (SAXS) was performed. SAXS is a powerful method to structurally analyze proteins in solution under physiological conditions [43]. In Figure 5, the SAXS analysis of wild-type Flal is visualized in comparison to the Walker $\mathrm{B}$ mutant $\left(\mathrm{Flal}^{\mathrm{E} 336 \mathrm{~A}}\right.$ ) in the presence of ATP and $\mathrm{Mg}^{2+}$. The experimental data was compared with theoretical SAXS curves from the crystal structures of monomeric and hexameric GspE. In order to obtain a reasonable fit of the monomeric GspE to the SAXS data from monomeric Flal, the N-terminal domain (in orange) had to be extended from the ATPase domain (green), which is an indication that there is a flexible conformation of these domains relative to one another. Flal $^{\mathrm{E} 336 \mathrm{~A}}$ with $\mathrm{ATP}$ clearly forms a hexameric ring similar to the one determined for GspE.

$A b$ initio structures for both complexes agree well with the GspE models. For calculating the structure of the hexameric protein, we used both no symmetry constraint and 6-fold symmetry. Even without symmetry constraints, we obtained the closed ring structure, but the conformation of the $\mathrm{N}$-terminal domains (orange) seems to be different for the single subunits. The SAXS data from Flal in monomeric and hexameric form can be analyzed by the Kratky plot (Figure S3) to determine amounts of intrinsic flexibility. In the monomeric form of Flal that is present in the cytoplasm, the amount of flexibility within the protein is much higher compared to the hexameric, membrane associated form. From this data, we propose that the N-terminal domains are flexible when Flal has a cytoplasmic localization but may adopt a more rigid conformation when the proteins attach to the membrane or membrane proteins.

\section{Liposome interaction studies}

The structure of GspE showed an accumulation of hydrophobic patches at the interface which probably interacts with membrane-integral components. The same hydrophobicity was observed in Flal models based on the GspE structures. Based on the 3-4 fold increase in Flal ATPase activity upon addition of archaeal tetraether lipids, it was essential to ascertain that a direct interaction between lipids and Flal occurs.

To this end, a liposome pull-down assay was performed in which Flal, Flal $^{\mathrm{K} 268 \mathrm{~A}}$ and $\mathrm{Flal}^{\mathrm{E} 336 \mathrm{~A}}$ were incubated either with $S$. acidocaldarius tetraether lipid liposomes (Figure 6A) or E. coli lipid liposomes (Figure 6B). In the case of the tetraether lipids, the Flal association with the liposomes was ATPdependent. When ATP was present, Flal $^{\mathrm{E} 336 \mathrm{~A}}$ associated most strongly with 
Ghosh et.al.

the tetraether liposomes whereas $\mathrm{Flal}^{\mathrm{K} 268 \mathrm{~A}}$ bound the least. The same results were observed when the same experiment was performed in the presence of AMP-PNP (Figure S4). These data imply that ATP binding by Flal is essential for its interaction with tetraether lipids. In contrast, the interaction of Flal with the $E$. coli lipids was independent of the presence or absence of ATP, showing that this is an unspecific interaction that is caused by the hydrophobic nature of the upper surface of the hexameric protein. 
Ghosh et.al.

\section{DISCUSSION}

Although archaeal flagella systems were identified some time ago, the role that the various flagellar subunits play during assembly and rotation and how they interact with each other during this process has not been elucidated [14, 18]. The secretion ATPase Flal is a central component of the flagellum assembly system. Previously, it was shown that Flal could hydrolyzes ATP under in vitro condition [26]. Genetic analysis revealed its importance in the assembly process. flal deletion mutants of $M$. maripaludis and $H$. salinarum were impaired in flagella assembly $[16,19,37]$. Furthermore, in $H$. salinarum it has been shown that flagellar rotation is dependent on the intercellular ATP concentration and not on the proton motive force, as is the case in bacteria [52]. These findings implicate Flal as an essential ATPase for flagellar assembly and/or rotation. However, to provide further insights into its roles, it is necessary to understand the molecular mechanism that Flal employs. Here, we demonstrated that Flal hydrolyzes ATP and undergoes an ATP-dependent oligomerization.

Computational analysis has identified the conserved ATP binding (Walker A), metal binding (Asp box), and ATP hydrolysis (Walker B) motifs in Flal. We demonstrated the importance of each of these predicted domains in ATP binding and hydrolysis by site-directed mutagenesis. ATP-hydrolyzing activity of Flal is more efficient using $\mathrm{Mn}^{2+}$ as the co-factor instead of $\mathrm{Mg}^{2+}$ or $\mathrm{Ca}^{2+}$. This preference for $\mathrm{Mn}^{2+}$ as co-factor is congruent with secretion ATPases and kinases characterized from $S$. solfataricus [26]. Our data also revealed that the ATPase activity of Flal displays positive cooperativity, indicating that interactions between subunits occur in an ATP-dependent manner. However, we found that MANT-ATP binding is non-cooperative, probably because ATP analogs bind the monomeric or dimeric state of Flal under in vitro conditions. Analytical gel filtration demonstrated that in the presence of a nonhydrolyzable ATP analogue the monomer shifted to a higher oligomer and SAXS confirmed that the higher molecular species was a hexamer.

Importantly, archaeal tetraether lipids were found to enhance the ATPase activity of Flal, indicating that the Flal transition state intermediate is possibly stabilized in an ATP-bound state. The interactions of the ATPase motor with membrane lipids may therefore help regulate its actions.

Our data thus provide the first substantial insights into archaeal Flal function and probably preface the understanding of a common mechanism of Flal homologues in the Archaea. Generally, these data suggest a hexameric state of Flal in its ATP-bound state, when it is involved in flagellum assembly. Collectively, these data provide the basis for a model for the mode of function of Flal (Figure 7). Under in vivo conditions, Flal hydrolyses ATP and provides energy to the AFAS. It is still a matter of contention, whether the energy gained in this process is utilized for flagellar assembly by directing the transiocation of structural components like flagellins or for the rotational movement of flagella or even for both.

Crystal structures of the archaeal secretion ATPase GspE, the $H$. pylori and $E$. coli hexameric T4S ATPases, as well as the hexameric PilT ATPase in the T4P assembly system of $P$. aeruginosa have been shown to use $\mathrm{N}$-terminal domain movement to facilitate closed ATP-bound and open ADP-bound hexameric conformations [27-28, 51, 53-55]. Furthermore, it has been 
Ghosh et.al.

postulated that these ATPases act as inner membrane gated transporters for structural proteins and may thus mediate the whole cycle of assembly by executing a conformational change from closed to open upon ATP hydrolysis. It is possible that ATP hydrolysis is closely coupled to flagellin export into the growing flagellar filament. In contrast to this idea, ATP hydrolysis of Flal might generate energy for the rotation of the flagellum as it was shown that in $H$. salinarum flagellar rotation is ATP dependent [52].

Understanding how components in AFAS function to effect proper assembly on the archaeal surface and also how they communicate to execute these functions are still at an early stage. The secretion ATPase Flal and polytopic membrane protein FlaJ are potentially involved in formation of the core of the assembly complex, and it has been postulated that on this Flal-J core is the main platform for flagellar assembly $[12,56]$. However, another incomplete ATPase, FlaH has also been postulated to function in association with the FlalJ core to facilitate the process of assembly, disassembly or rotation. Understanding the biochemical and structural features of the Flal protein provides a basis to understand the function that this protein fulfills in AFAS which can be transferred to homologous ATPases from other T4P systems of bacteria.

\section{Acknowledgements}

We thank Benjamin Meyer for isolating the archaeal lipids. AG received a Max Planck Postdoctoral fellowship and SVA was supported by a VIDI grant of the Dutch Science Organization (NWO) and intramural funds of the Max Planck Society. SH and JAT T4P system efforts are supported by National Institute of Health [AI022160] and microbial complex SAXS efforts are supported by the ENIGMA Program of the Department of Energy, Office of Biological and Environmental Research, through contract DE-AC02-05CH11231 with Lawrence Berkeley National Laboratory and by National Institutes of Health grant AI022160. The SIBYLS beamline (BL12.3.1) at the Advanced Light Source is supported by United States Department of Energy program Integrated Diffraction Analysis Technologies (IDAT) DE-AC02-05CH11231. We thank Michal Hammel for expert SAXS data collection assistance. We thank Andrew Bozarth for critical reading of the manuscript. 
Ghosh et.al.

\section{REFERENCES}

1 Bardy, S. L. and Jarrell, K. F. (2003) Cleavage of preflagellins by an aspartic acid signal peptidase is essential for flagellation in the archaeon Methanococcus voltae. Mol Microbiol. 50, 1339-1347

2 Macnab, R. M. (2004) Type III flagellar protein export and flagellar assembly. Biochim Biophys Acta. 1694, 207-217

3 Hansen, J. K. and Forest, K. T. (2006) Type IV pilin structures: insights on shared architecture, fiber assembly, receptor binding and type II secretion. J Mol Microbiol Biotechnol. 11, 192-207

4 Albers, S. V. and Pohlschroder, M. (2009) Diversity of archaeal type IV pilinlike structures. Extremophiles. 13, 403-410

5 Pohlschroder, M., Ghosh, A., Tripepi, M. and Albers, S. V. (2011) Archaeal type IV pilus-like structures-evolutionarily conserved prokaryotic surface organelles. Curr Opin Microbiol

6 Marwan, W., Alam, M. and Oesterhelt, D. (1991) Rotation and switching of the flagellar motor assembly in Halobacterium halobium. J Bacteriol. 173, 1971-1977 7 Szabo, Z., Sani, M., Groeneveld, M., Zolghadr, B., Schelert, J., Albers, S. V., Blum, P., Boekema, E. J. and Driessen, A. J. (2007) Flagellar motility and structure in the hyperthermoacidophilic archaeon Sulfolobus solfataricus. J Bacteriol. 189, 43054309

8 Lewus, P. and Ford, R. M. (1999) Temperature-sensitive motility of Sulfolobus acidocaldarius influences population distribution in extreme environments. J Bacteriol. 181, 4020-4025

9 Zolghadr, B., Klingl, A., Koerdt, A., Driessen, A. J., Rachel, R. and Albers, S. V. (2010) Appendage-mediated surface adherence of Sulfolobus solfataricus. J Bacteriol. 192, 104-110

10 Koerdt, A., Godeke, J., Berger, J., Thormann, K. M. and Albers, S. V. (2010) Crenarchaeal Biofilm Formation under Extreme Conditions. PLoS One. 5, e14104 11 Bellack, A., Huber, H., Rachel, R., Wanner, G. and Wirth, R. (2010) Methanocaldococcus villosus sp. nov., a heavily flagellated archaeon adhering to surfaces and forming cell-cell contacts. Int J Syst Evol Microbiol

$12 \mathrm{Ng}, \mathrm{S}$. Y., Chaban, B. and Jarrell, K. F. (2006) Archaeal flagella, bacterial flagella and type IV pili: a comparison of genes and posttranslational modifications. J Mol Microbiol Biotechnol. 11, 167-191

13 Trachtenberg, S. and Cohen-Krausz, S. (2006) The archaeabacterial flagellar filament: a bacterial propeller with a pilus-like structure. J Mol Microbiol Biotechnol. 11, 208-220

14 Craig, L., Pique, M. E. and Tainer, J. A. (2004) Type IV pilus structure and bacterial pathogenicity. Nat Rev Microbiol. 2, 363-378

$15 \mathrm{Ng}, \mathrm{S}$. Y., Zolghadr, B., Driessen, A. J., Albers, S. V. and Jarrell, K. F. (2008) Cell surface structures of archaea. J Bacteriol. 190, 6039-6047

16 Chaban, B., Ng, S. Y., Kanbe, M., Saltzman, I., Nimmo, G., Aizawa, S. and Jarrell, K. F. (2007) Systematic deletion analyses of the fla genes in the flagella operon identify several genes essential for proper assembly and function of flagella in the archaeon, Methanococcus maripaludis. Mol Microbiol. 66, 596-609

17 Albers, S. V., Szabo, Z. and Driessen, A. J. (2003) Archaeal homolog of bacterial type IV prepilin signal peptidases with broad substrate specificity. J Bacteriol. 185, 3918-3925 
Ghosh et.al.

18 Peabody, C. R., Chung, Y. J., Yen, M. R., Vidal-Ingigliardi, D., Pugsley, A. P. and Saier, M. H., Jr. (2003) Type II protein secretion and its relationship to bacterial type IV pili and archaeal flagella. Microbiology. 149, 3051-3072

19 Patenge, N., Berendes, A., Engelhardt, H., Schuster, S. C. and Oesterhelt, D.

(2001) The fla gene cluster is involved in the biogenesis of flagella in Halobacterium salinarum. Mol Microbiol. 41, 653-663

20 Cohen-Krausz, S. and Trachtenberg, S. (2002) The structure of the archeabacterial flagellar filament of the extreme halophile Halobacterium salinarum R1M1 and its relation to eubacterial flagellar filaments and type IV pili. J Mol Biol. 321, 383-395

21 Cohen-Krausz, S. and Trachtenberg, S. (2008) The flagellar filament structure of the extreme acidothermophile Sulfolobus shibatae B12 suggests that archaeabacterial flagella have a unique and common symmetry and design. J Mol Biol. 375, 1113-1124

22 Mudrak, B. and Kuehn, M. J. (2010) Specificity of the type II secretion systems of enterotoxigenic Escherichia coli and Vibrio cholerae for heat-labile enterotoxin and cholera toxin. J Bacteriol. 192, 1902-1911

23 Guo, M., Jin, S., Sun, D., Hew, C. L. and Pan, S. Q. (2007) Recruitment of conjugative DNA transfer substrate to Agrobacterium type IV secretion apparatus. Proc Natl Acad Sci U S A. 104, 20019-20024

24 Ghosh, A. and Albers, S. V. (2011) Assembly and function of the archaeal flagellum. Biochem Soc Trans. 39, 64-69

25 Bardy, S. L., Eichler, J. and Jarrell, K. F. (2003) Archaeal signal peptides--a comparative survey at the genome level. Protein Sci. 12, 1833-1843

26 Albers, S. V. and Driessen, A. J. (2005) Analysis of ATPases of putative secretion operons in the thermoacidophilic archaeon Sulfolobus solfataricus.

Microbiology. 151, 763-773

27 Yamagata, A. and Tainer, J. A. (2007) Hexameric structures of the archaeal secretion ATPase GspE and implications for a universal secretion mechanism. EMBO J. 26, 878-890

28 Yeo, H. J., Savvides, S. N., Herr, A. B., Lanka, E. and Waksman, G. (2000) Crystal structure of the hexameric traffic ATPase of the Helicobacter pylori type IV secretion system. Mol Ce1l. 6, 1461-1472

29 Craig, L., Taylor, R. K., Pique, M. E., Adair, B. D., Arvai, A. S., Singh, M., Lloyd, S. J., Shin, D. S., Getzoff, E. D., Yeager, M., Forest, K. T. and Tainer, J. A. (2003) Type IV pilin structure and assembly: X-ray and EM analyses of Vibrio cholerae toxin-coregulated pilus and Pseudomonas aeruginosa PAK pilin. Mol Cell. 11, 1139-1150

30 Craig, L., Volkmann, N., Arvai, A. S., Pique, M. E., Yeager, M., Egelman, E. H. and Tainer, J. A. (2006) Type IV pilus structure by cryo-electron microscopy and crystallography: implications for pilus assembly and functions. Mol Cell. 23, 651-662 31 Planet, P. J., Kachlany, S. C., DeSalle, R. and Figurski, D. H. (2001)

Phylogeny of genes for secretion NTPases: identification of the widespread tadA subfamily and development of a diagnostic key for gene classification. Proc Natl Acad Sci U S A. 98, 2503-2508

32 Possot, O. and Pugsley, A. P. (1994) Molecular characterization of PulE, a protein required for pullulanase secretion. Mol Microbiol. 12, 287-299

33 Chiang, P., Sampaleanu, L. M., Ayers, M., Pahuta, M., Howell, P. L. and Burrows, L. L. (2008) Functional role of conserved residues in the characteristic 
Ghosh et.al.

secretion NTPase motifs of the Pseudomonas aeruginosa type IV pilus motor proteins PilB, PilT and PilU. Microbiology. 154, 114-126

34 Jakovljevic, V., Leonardy, S., Hoppert, M. and Sogaard-Andersen, L. (2008) PilB and PilT are ATPases acting antagonistically in type IV pilus function in Myxococcus xanthus. J Bacteriol. 190, 2411-2421

35 Turner, L. R., Lara, J. C., Nunn, D. N. and Lory, S. (1993) Mutations in the consensus ATP-binding sites of XcpR and PilB eliminate extracellular protein secretion and pilus biogenesis in Pseudomonas aeruginosa. J Bacteriol. 175, 4962 4969

36 Schlesner, M., Miller, A., Streif, S., Staudinger, W. F., Muller, J., Scheffer, B., Siedler, F. and Oesterhelt, D. (2009) Identification of Archaea-specific chemotaxis proteins which interact with the flagellar apparatus. BMC Microbiol. 9, 56

37 Thomas, N. A., Mueller, S., Klein, A. and Jarrell, K. F. (2002) Mutants in flaI and flaJ of the archaeon Methanococcus voltae are deficient in flagellum assembly. Mol Microbiol. 46, 879-887

38 Miroux, B. and Walker, J. E. (1996) Over-production of proteins in Escherichia coli: mutant hosts that allow synthesis of some membrane proteins and globular proteins at high levels. J Mol Biol. 260, 289-298

39 Lanzetta, P. A., Alvarez, L. J., Reinach, P. S. and Candia, O. A. (1979) An improved assay for nanomole amounts of inorganic phosphate. Anal Biochem. 100, 95-97

40 Albers, S. V., Konings, W. N. and Driessen, A. J. (2006) Membranes of Thermophiles and Other Extremophiles. In Methods in Microbiology (Rainey, ed.)^eds.). pp. 161-171

41 Selyunin, A. S., Sutton, S. E., Weigele, B. A., Reddick, L. E., Orchard, R. C., Bresson, S. M., Tomchick, D. R. and Alto, N. M. (2011) The assembly of a GTPasekinase signalling complex by a bacterial catalytic scaffold. Nature. 469, 107-111 42 Hura, G. L., Menon, A. L., Hammel, M., Rambo, R. P., Poole, F. L., 2nd, Tsutakawa, S. E., Jenney, F. E., Jr., Classen, S., Frankel, K. A., Hopkins, R. C., Yang, S. J., Scott, J. W., Dillard, B. D., Adams, M. W. and Tainer, J. A. (2009) Robust, high-throughput solution structural analyses by small angle X-ray scattering (SAXS). Nat Methods. 6, 606-612

43 Putnam, C. D., Hammel, M., Hura, G. L. and Tainer, J. A. (2007) X-ray solution scattering (SAXS) combined with crystallography and computation: defining accurate macromolecular structures, conformations and assemblies in solution. Q Rev Biophys. 40, 191-285

44 Guinier, A.F., F. (1995) Small Angle Scattering of X-rays. Wiley Interscience, New York

45 Svergun, D. I. (1992) Determination of the regularization parameter in indirect-transform methods using perceptual criteria. J Appl Crystal. 25, 495-503 46 Svergun, D. I., Petoukhov, M. V. and Koch, M. H. (2001) Determination of domain structure of proteins from X-ray solution scattering. Biophys J. 80, 2946-2953 47 Schneidman-Duhovny, D., Hammel, M. and Sali, A. (2010) FoXS: a web server for rapid computation and fitting of SAXS profiles. Nucleic Acids Res. 38 Suppl, W540-544

48 Camberg, J. L., Johnson, T. L., Patrick, M., Abendroth, J., Hol, W. G. and Sandkvist, M. (2007) Synergistic stimulation of EpsE ATP hydrolysis by EpsL and acidic phospholipids. EMBO J. 26, 19-27 
Ghosh et.al.

49 Shiue, S. J., Kao, K. M., Leu, W. M., Chen, L. Y., Chan, N. L. and Hu, N. T. (2006) XpsE oligomerization triggered by ATP binding, not hydrolysis, leads to its association with XpsL. EMBO J. 25, 1426-1435

50 Patrick, M., Korotkov, K. V., Hol, W. G. and Sandkvist, M. (2011)

Oligomerization of EpsE coordinates residues from multiple subunits to facilitate ATPase activity. J Biol Chem

51 Misic, A. M., Satyshur, K. A. and Forest, K. T. (2010) P. aeruginosa PilT structures with and without nucleotide reveal a dynamic type IV pilus retraction motor. J Mol Biol. 400, 1011-1021

52 Streif, S., Staudinger, W. F., Marwan, W. and Oesterhelt, D. (2008) Flagellar rotation in the archaeon Halobacterium salinarum depends on ATP. J Mol Biol. 384, $1-8$

53 Krause, S., Pansegrau, W., Lurz, R., de la Cruz, F. and Lanka, E. (2000) Enzymology of type IV macromolecule secretion systems: the conjugative transfer regions of plasmids RP4 and R388 and the cag pathogenicity island of Helicobacter pylori encode structurally and functionally related nucleoside triphosphate hydrolases. J Bacteriol. 182, 2761-2770

54 Krause, S., Barcena, M., Pansegrau, W., Lurz, R., Carazo, J. M. and Lanka, E. (2000) Sequence-related protein export NTPases encoded by the conjugative transfer region of RP4 and by the cag pathogenicity island of Helicobacter pylori share similar hexameric ring structures. Proc Natl Acad Sci U S A. 97, 3067-3072

55 Gomis-Ruth, F. X., Moncalian, G., Perez-Luque, R., Gonzalez, A., Cabezon, E., de la Cruz, F. and Coll, M. (2001) The bacterial conjugation protein TrwB resembles ring helicases and F1-ATPase. Nature. 409, 637-641

56 Albers, S. V., Szabo, Z. and Driessen, A. J. (2006) Protein secretion in the Archaea: multiple paths towards a unique cell surface. Nat Rev Microbiol. 4, 537-547 


\section{Ghosh et.al.}

\section{Table 1 Primers and plasmids used for assays}

\begin{tabular}{|c|c|c|}
\hline $\begin{array}{l}\text { Bacterial strains, } \\
\text { primers and plasmids }\end{array}$ & Relevant characteristics & $\begin{array}{l}\text { Source or } \\
\text { reference }\end{array}$ \\
\hline \multicolumn{3}{|l|}{ Strains } \\
\hline \multicolumn{3}{|c|}{10 mo } \\
\hline $\mathrm{Dh} 5 \alpha$ & $12 \mathrm{f} 80 \mathrm{~d} /$ lacZDM15 D(lacZYA-argF)U169 recAl endA1 hsdR17 (rK2 mK1) supE44 thi-1 gyrA relA1 & GIBCO BRL \\
\hline B121(DE3)- RIL & B F- ompT hsdS(rB- mB-) dcm + Tetr E. coli gal $\lambda(\mathrm{DE} 3)$ endA Hte [argU ileY leuW Camr] & Stratagene \\
\hline Walker cells- & F-ompT gal hsdSB (rB-mB-) dcm lon_DE3 endA Hte [argU ileY leuW Camr] & \\
\hline RIL (C43) & & \\
\hline \multicolumn{3}{|l|}{ Sulfolobus acidocaldarius } \\
\hline DSM639 & Hyperthermo-acidophilic crenarchaeon which grows optimally at $80^{\circ} \mathrm{C}$ and $\mathrm{pH} 2-3$ & DSMZ \\
\hline \multicolumn{3}{|c|}{ 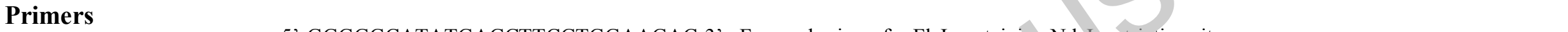 } \\
\hline FlaI713 & 5'-GGGGGCATATGAGCTTCGTGGAAGAC-3'; Forward primer for FlaI containing NdeI restriction site & This study \\
\hline FlaI714 & 5'-GGGGGCTCGAGTCAAATATTACTGACATATTTTATC-3'; Reverse primer for FlaI containing XhoI restriction site & This study \\
\hline FlaI728 & 5’- CCCCCGAATTCGATGAGCTTCGTGGAAGAC-3’; Forward primer for FlaI containing EcoRI restriction site & This study \\
\hline FlaI729 & 5'- CCCCCAAGCTTTCAAATATTACTGACATATTTTATC-3'; Reverse primer for FlaI containing HindIII restriction site & This study \\
\hline F19I747 & 5’- ATCTGGAGCGACAACTAC-3’; Overlapping internal forward primer for $\mathrm{K}_{268}$ A mutation in FlaI & This study \\
\hline Flal $/ 42$ & 5'- AATGTAGTTGTCGCTCCAG-3'; Overlapping internal reverse primer for $\mathrm{K}_{268}$ A mutation in FlaI & This study \\
\hline FlaI743 & 5’- TATTGAGGCGACTCCAG-3’; Overlapping internal forward primer for $\mathrm{D}_{290}$ A mutation in FlaI & This study \\
\hline FlaI782 & 5'- TCTGGAGTCGCCTCAATA-3'; Overlapping internal reverse primer for $\mathrm{D}_{290}$ A mutation in FlaI & This study \\
\hline FlaI783 & 5’-ACTTGTGGGAGCAATTAGAG-3'; Overlapping internal forward primer for E ${ }_{336}$ A mutation in FlaI & This study \\
\hline FlaI784 & 5'- CTTTGTCTCTAATTGCTCCCACAAG-3'; Overlapping internal reverse primer for $\mathrm{E}_{336} \mathrm{~A}$ mutation in FlaI & This study \\
\hline FlaI785 & & \\
\hline \multicolumn{3}{|l|}{ Plasmids } \\
\hline pETDuet-1 & $\mathrm{Amp}^{\mathrm{r}}, \mathrm{Car}^{\mathrm{r}}$, expression plasmid containing replicon ColE1 (pBR322) and two MCS (MCS1 and MCS2) & Novagen \\
\hline pSVA251 & $\mathrm{Amp}^{\mathrm{r}}, \mathrm{Car}^{\mathrm{r}}, \mathrm{pETDuet}-1$ carrying untagged FlaI in MCS2 using restriction sites NdeI-XhoI & This study \\
\hline pSVA263 & Amp $^{r}$, Car $^{r}$, pETDuet-1 carrying N-terminal His-tagged FlaI in MCS1 using restriction sites EcoRI-HindIII & This study \\
\hline pSVA265 & $\begin{array}{l}\text { Amp }{ }^{r}, \text { Car }^{r} \text {, pETDuet-1 carrying N-terminal His-tagged FlaI }\left(\mathrm{K}_{268} \mathrm{~A}\right) \text { in MCS1 using restriction sites EcoRI- } \\
\text { HindIII }\end{array}$ & This study \\
\hline pSVA307 & $\begin{array}{l}\text { Amp }{ }^{r}, \text { Car }^{r}, \text { pETDuet-1 carrying N-terminal His-tagged FlaI( }\left(D_{290} A\right) \text { in MCS1 using restriction sites EcoRI- } \\
\text { HindIII }\end{array}$ & This study \\
\hline pSVA308 & Amp $^{r}$, Car $^{r}$, pETDuet-1 carrying N-terminal His-tagged FlaI $\left(E_{336} \mathrm{~A}\right)$ in MCS1 using restriction sites EcoRI- & This study \\
\hline pSVA314 & $\begin{array}{l}\text { Amp }{ }^{r}, \text { Car }^{r} \text {, pETDuet-1 carrying N-terminal His-tagged FlaI }\left(\mathrm{K}_{268} \mathrm{~A}, \mathrm{E}_{336} \mathrm{~A}\right) \text { in } \mathrm{MCS} 1 \text { using restriction sites } \\
\text { EcoRI-HindIII }\end{array}$ & This study \\
\hline
\end{tabular}


Ghosh et.al.

Figures and figure legends

A

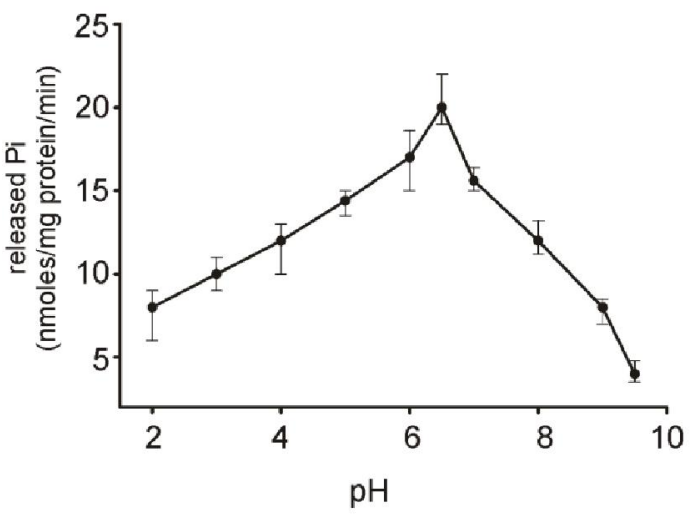

C

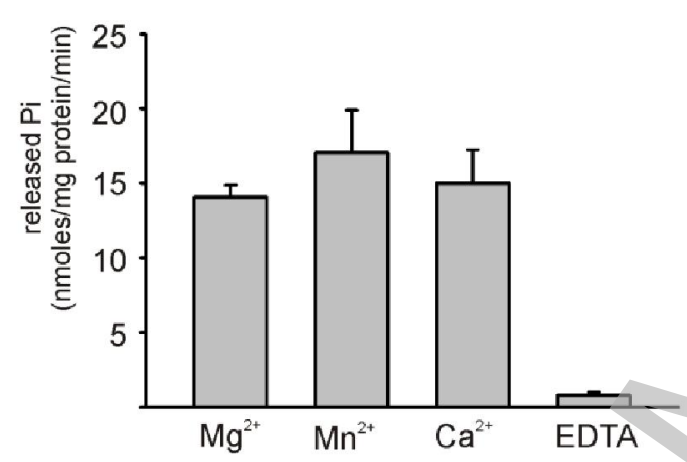

E

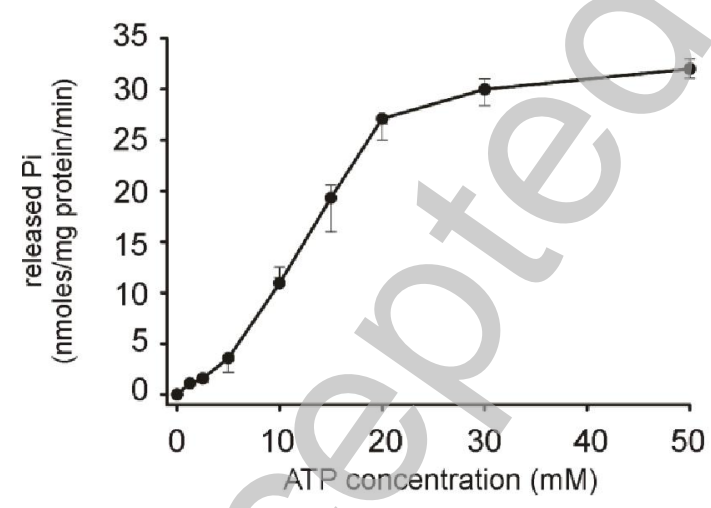

$\mathrm{B}$

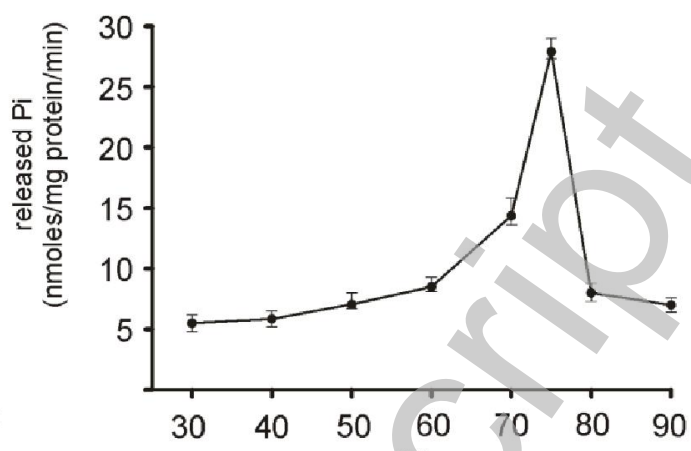

$\mathrm{D}$

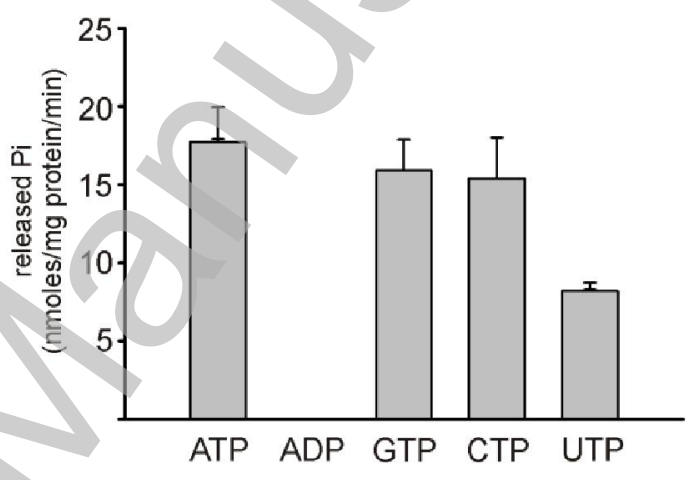

F

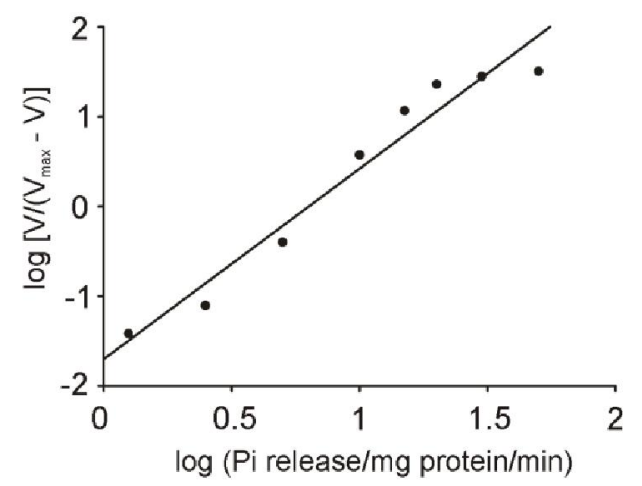

Figure 1 ATPase activity of Flal under various conditions

Total Pi released upon ATP (NTP) hydrolysis was measured by the malachite green assay. (A) Influence of $\mathrm{pH}$ on Flal ATPase activity. (B) Influence of temperature on Flal ATPase activity. (C) Preference for optimal divalent metal ion as cofactor in Flal ATPase activity. The final concentration of protein used in the assays was $1 \mu \mathrm{M}$ and the final concentration of metal ions was $5 \mathrm{mM}$. (D) Analysis of optimal substrate for hydrolysis. NTPs were added to a final concentration of $5 \mathrm{mM}$. (E) Flal ATPase activity as a function of the ATP concentration measured at $70^{\circ} \mathrm{C}$ with $1 \mu \mathrm{M}$ of Flal. (F) The same Flal ATPase 
Ghosh et.al.

activity plotted according to Hill equation (Hill equation $=2.0$ ). All experiments were performed in triplicate and standard deviations are indicated.

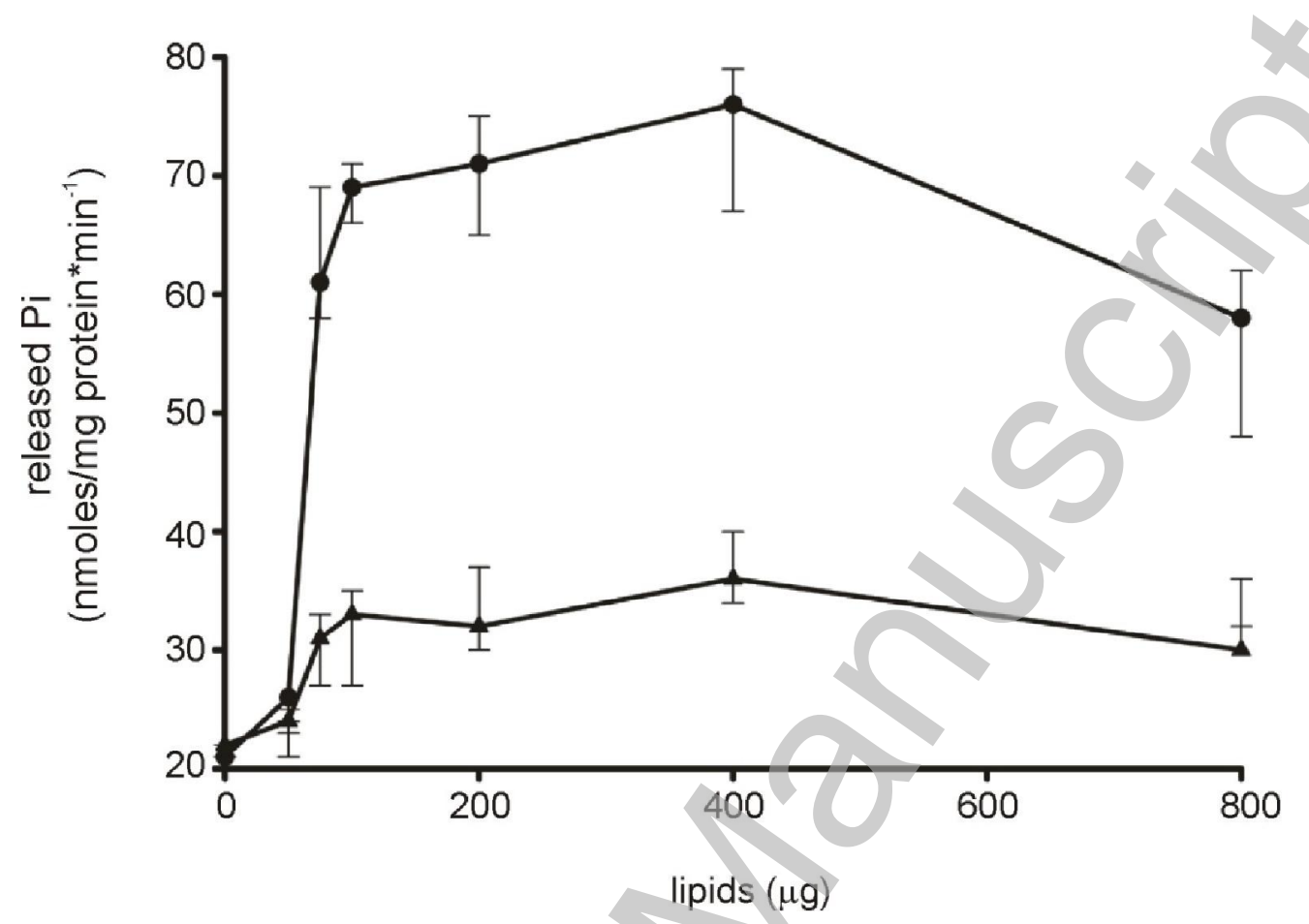

Figure 2 Effect of tetraether lipids from S. acidocaldarius and total lipids from E.coli on Flal ATPase activity

ATP hydrolysis was measured at $70^{\circ} \mathrm{C}$ with $1 \mu \mathrm{M}$ of purified Flal in presence of different concentrations $(40 \mu \mathrm{g}-800 \mu \mathrm{g})$ of isolated tetraether-linked lipids from Sulfolobus acidocaldarius and total lipids from E.coli against respective controls in which an equivalent amount of respective lipids was present in the assay mixture without any protein and treated in a similar manner as for the enzymatic reaction described in materials and methods. All experiments were performed in triplicate and standard deviations are indicated. 
Ghosh et.al.

A

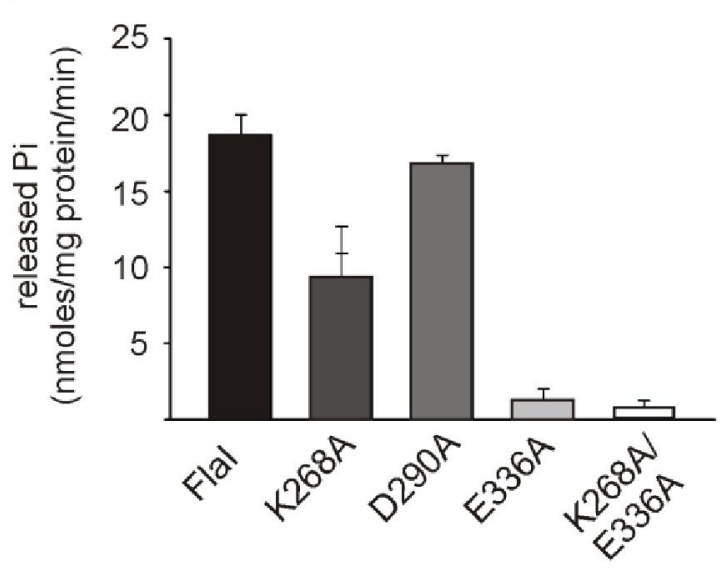

$\mathrm{B}$

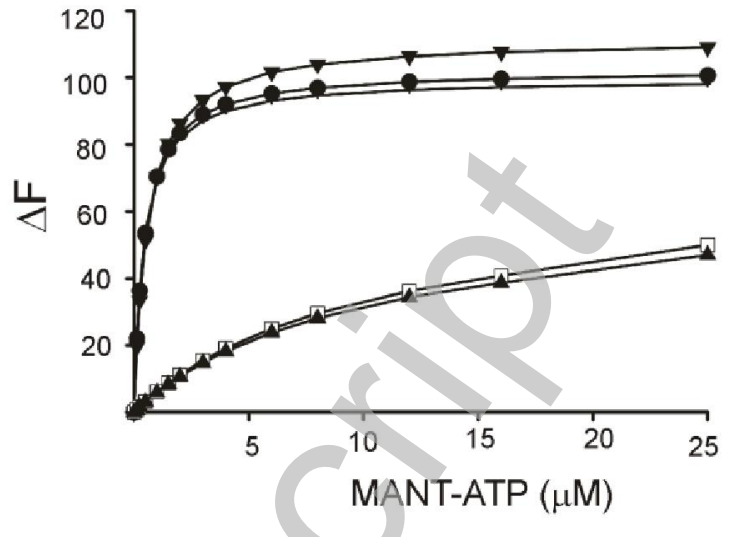

Figure $\mathbf{3}$ Characterization of ATP-binding and hydrolysis motifs in Flal (A) Comparative ATP-hydrolyzing activity of Walker A (Flai ${ }^{\mathrm{K} 268 \mathrm{~A}}$ ), Asp- box (Flal ${ }^{\mathrm{D} 290 \mathrm{~A}}$ ), Walker B (Flal ${ }^{\mathrm{E} 336 \mathrm{~A}}$ ), and Walker A \& B double (Flal ${ }^{\mathrm{K} 268 \mathrm{~A}}$, ${ }^{2336 \mathrm{~A}}$ ) mutants against the wild type Flal protein (black). (B) Analysis of the binding of MANT-ATP by wild type Flal and the mutants as monitored by FRET. The change in fluorescence $(\triangle F)$ upon MANT-ATP binding is shown as a function of the concentration of MANT-ATP. Fluorescence spectra were corrected for the fluorescence of unbound MANT-ATP. The $K_{d}$ values were calculated for each of the mutants and wild type Flal. Closed circles, Flal; closed triangle, $\mathrm{Flal}^{\mathrm{K} 268 \mathrm{~A}, \mathrm{E} 336 \mathrm{~A}}$ : open rectangle, $\mathrm{Flal}^{\mathrm{K} 268 \mathrm{~A}}$; vertical stripe, $\mathrm{Flal}^{\mathrm{D} 290 \mathrm{~A}}$; closed diamonds, Flal ${ }^{\mathrm{E} 336 \mathrm{~A}}$. 
Ghosh et.al.

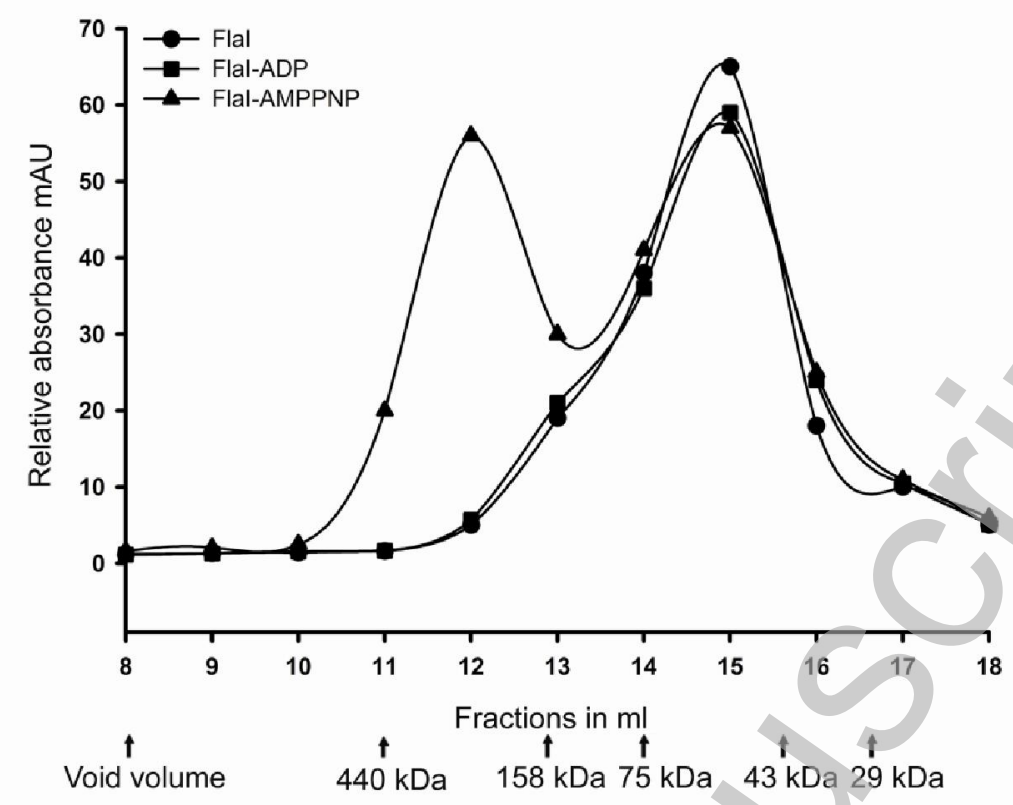

Flal

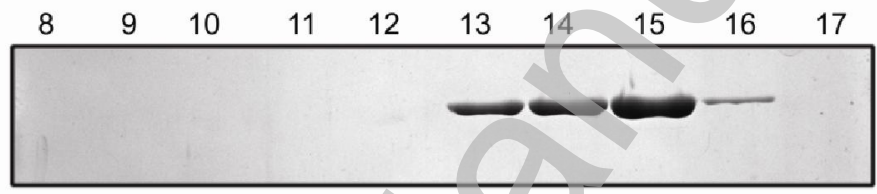

Flal-ADP

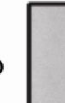

Flal-AMPPNP
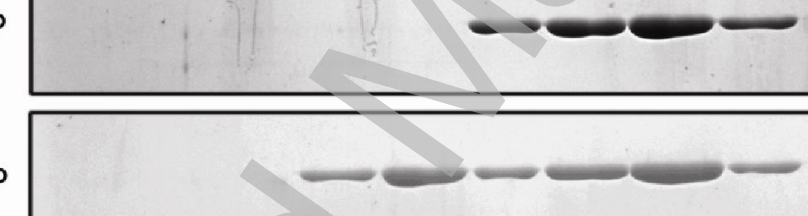

Figure 4 Size exclusion chromatography of Flal, Flal with ADP and Flal with AMP-PNP

Flal, Flal in the presence of ADP or AMP-PNP were analyzed on an analytical size exclusion column (Superdex 200). The elution fractions were analyzed on a SDS-PAGE and stained with Coommassie. Arrows indicate the position of the marker proteins used to calibrate the column. Prior to analytical gel filtration the purified Flal $(1 \mu \mathrm{M})$ was pre-incubated at $50^{\circ} \mathrm{C}$ for $10 \mathrm{~min}$ followed by an incubation at $4^{\circ} \mathrm{C}$ for $6 \mathrm{~h}$ with either $1 \mathrm{mM} \mathrm{AMP-PNP}$ or ADP, and 10 $\mathrm{mM} \mathrm{MgCl}$. (Molecular weight standards used are: Ribonuclease $A \mathrm{M}_{\mathrm{r}}$ 13,700; Carboxy anhydrase $M_{r}$ 29,000; Ovalbumin $M_{r} 43,000$; Conalbumin $M_{r} 75,000$; Aldolase $M_{r}$ 158,000; Ferritin $M_{r}$ 440,000). 
Ghosh et.al.

A

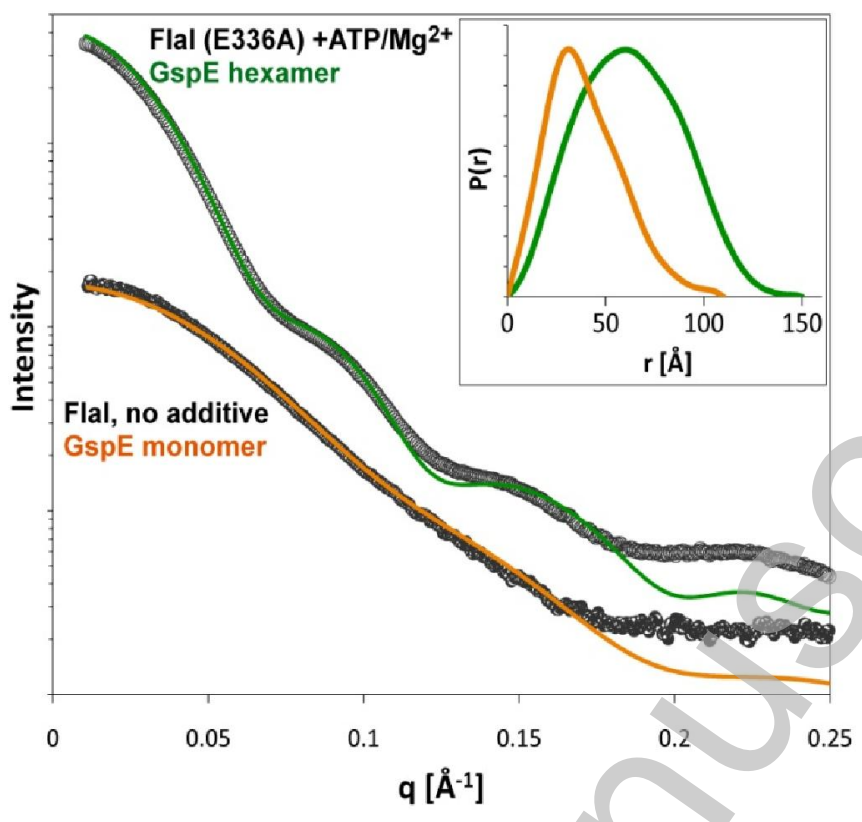

$$
\begin{array}{cc}
\text { Flal, no additive } & \text { Flal }(\mathrm{E} 336 \mathrm{~A})+\mathrm{ATP} / \mathrm{Mg}^{2+} \\
\text { GspE monomer } & \text { GspE hexamer }
\end{array}
$$
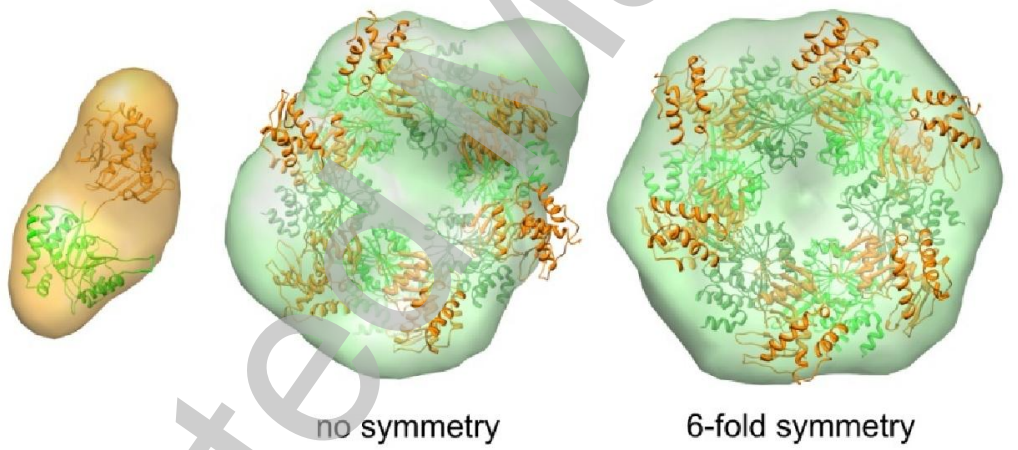

Figure 5 Solution structures of S. acidocaldarius Flal with and without ATP

(A) Experimental scattering profiles are shown for wild-type Flal (lower curve) and for the Walker B mutant Flal ${ }^{\mathrm{E} 36 \mathrm{~A}}$ in the presence of ATP and $\mathrm{MgCl}_{2}$ (upper curve). The theoretical scattering from $A$. fulgidus $\mathrm{GspE}$ is shown in green for a hexamer and in orange for a monomer. In the presence of ATP and $\mathrm{MgCl}_{2} \mathrm{Flal}$ forms a hexameric structure similar to the hexameric ring of GspE, without nucleotide this ring falls apart in what seems to be similar to the GspE monomer. Inset. Distance distribution functions $P(r)$ of the Flal hexamer and monomer computed from experimental SAXS data are shown in green and orange, respectively. The $P(r)$ functions are normalized to unity at their maxima.

(B) Average of $15 a b$ initio models for Flal with and without ATP overlaid with the crystal structures of hexameric and monomeric GspE, respectively. The model for hexameric Flal was calculated without and with applied 6-fold symmetry in the modeling. 
Ghosh et.al.

A S. acidocaldarius lipids

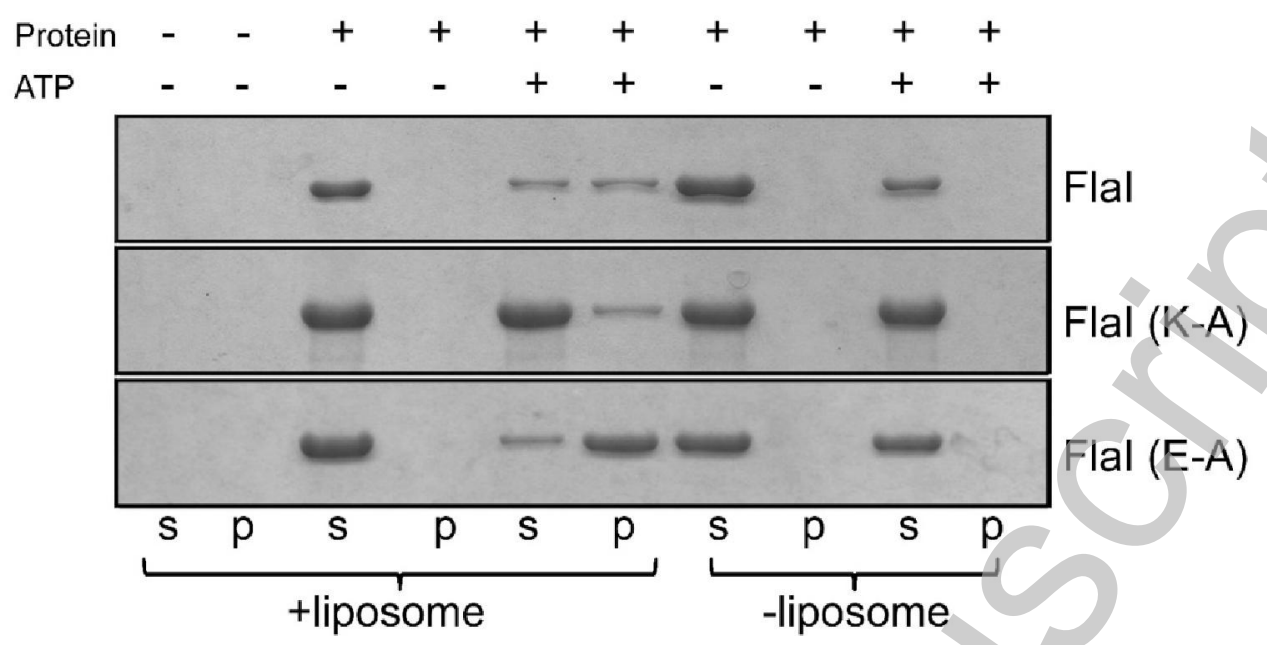

B E. coli lipids

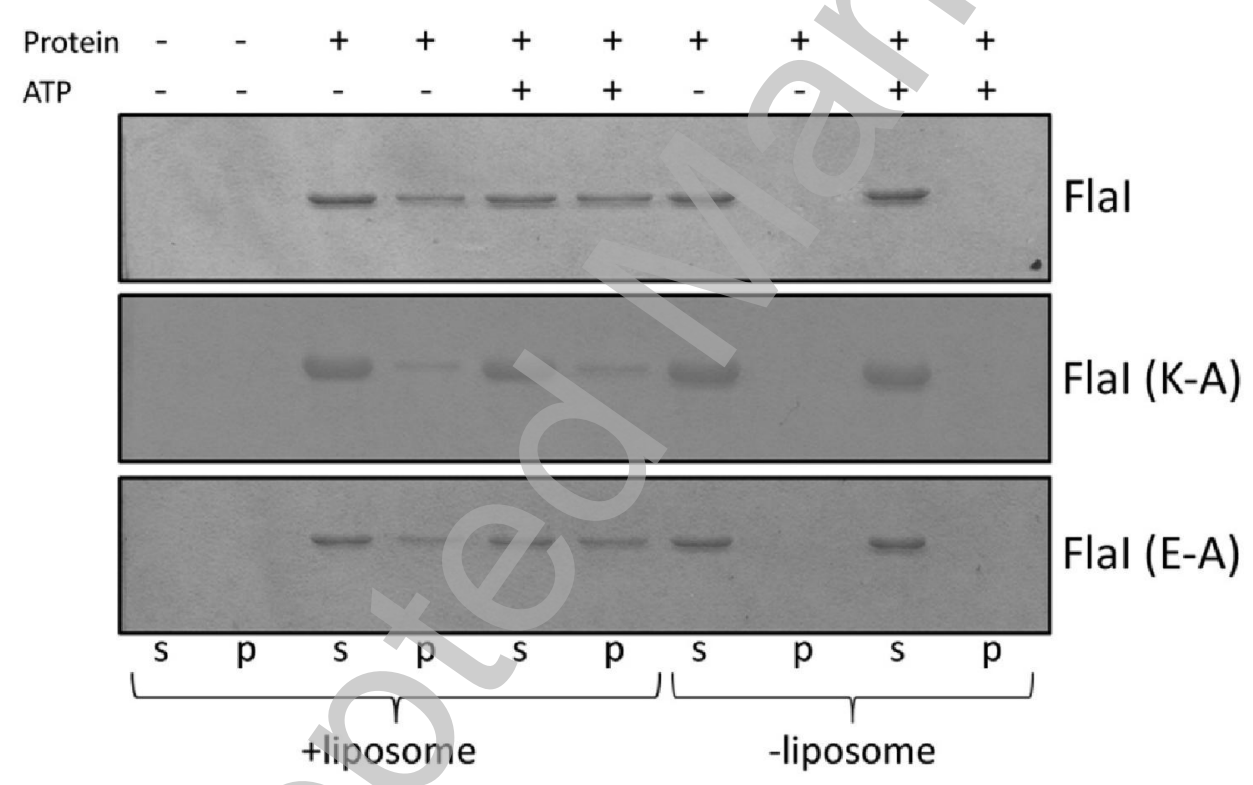

Figure 6 Liposome pull-down assay of Flal in the presence of $S$. acidocaldarius tetraether lipids and E.coli lipid extract

The interaction of either Flal, Flal ${ }^{\mathrm{K} 268 \mathrm{~A}}$ or $\mathrm{Flal}^{\mathrm{E} 336 \mathrm{~A}}$ protein was tested either with $S$. acidocaldarius tetraether liposomes (A) or lipids from E. coli (B) in presence or absence of ATP. After centrifugation, proteins remaining in the supernatant (s) or those associated with liposomes in the pellet $(p)$ were separated on an SDS-PAGE. 


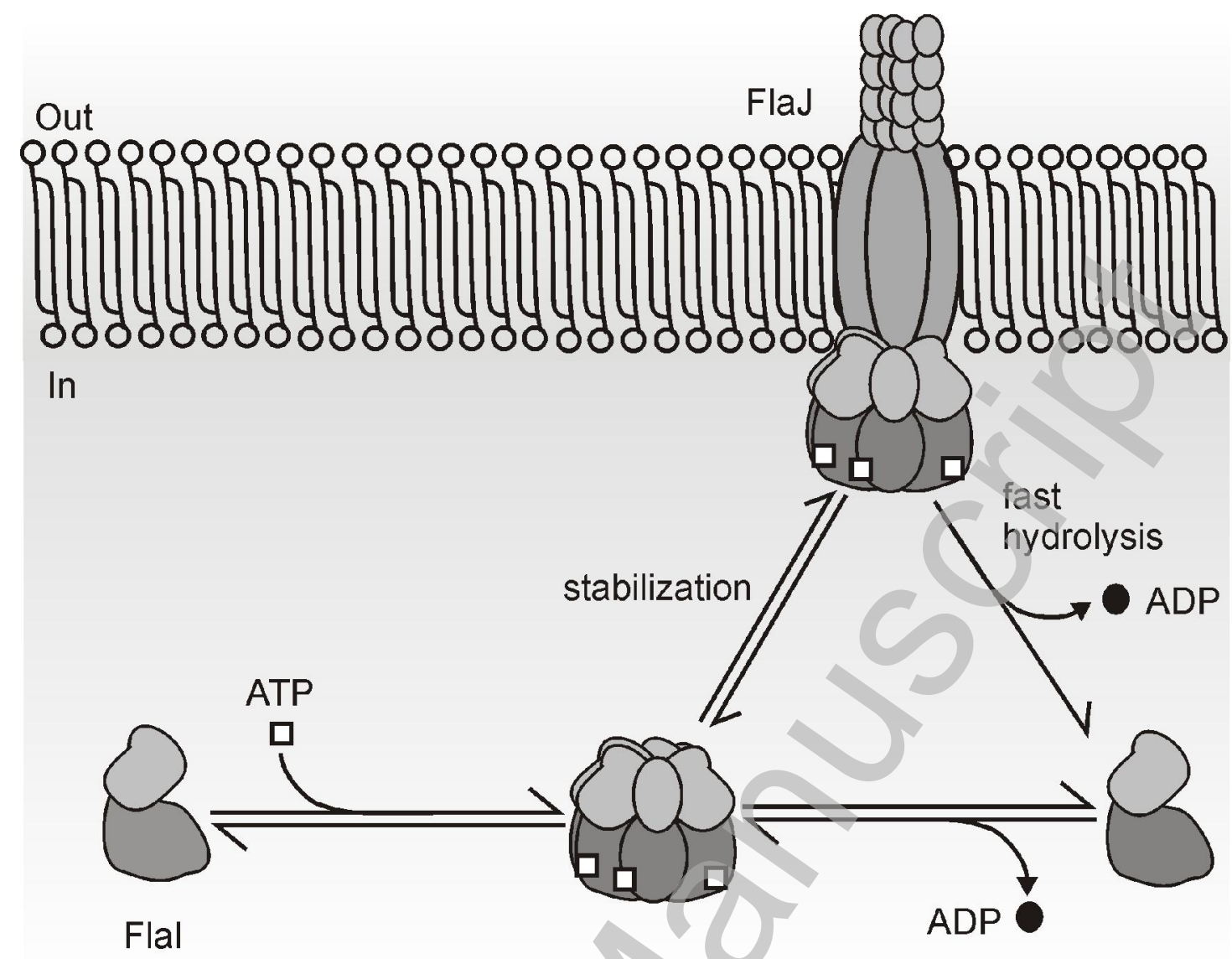

Figure 7 Model describing the sequence of events that Flal undergoes in AFAS as inferred from this study

Flal undergoes ATP-dependent oligomerization and attains a hexameric conformation. This ATP bound hexameric Flal is possibly stabilized via interactions with other membrane components (like FlaJ) in AFAS and also with tetraether lipids in the membrane. ATPase activity of Flal, already associated to the macromolecular archaeal flagella assembly complex, might provide energy to drive the flagellum assembly and/or rotation. 